\title{
Hypoxia induces endothelial-mesenchymal transition in pulmonary vascular remodeling
}

\author{
BO ZHANG ${ }^{*}$, WEN NIU* ${ }^{*}$ HAI-YING DONG, MAN-LING LIU, YING LUO and ZHI-CHAO LI \\ Department of Pathophysiology, Fourth Military Medical University, Xi'an, Shaanxi 710032, P.R. China
}

Received May 7, 2017; Accepted March 1, 2018

DOI: 10.3892/ijmm.2018.3584

\begin{abstract}
It is well established that hypoxia induces epithelial-mesenchymal transition in vitro and in vivo. However, the role of hypoxia in endothelial-mesenchymal transition (EndMT), an important process in the pathogenesis of pulmonary hypertension, is not well-characterized. The present study demonstrated a significant downregulation of the endothelial marker CD31 and its co-localization with a mesenchymal marker, $\alpha$-smooth muscle actin ( $\alpha$-SMA), in the intimal layer of small pulmonary arteries of rats exposed to chronic hypoxia. These results suggest a possible role of hypoxia in inducing EndMT in vivo. Consistent with these observations, pulmonary microvascular endothelial cells (PMVECs) cultured under hypoxic conditions exhibited a significant decrease in CD31 expression, alongside a marked increase in the expression of $\alpha$-SMA and two other mesenchymal markers, collagen (Col) 1A1 and Col3A1. In addition, hypoxia promoted the proliferation and migration of $\alpha$-SMA-expressing mesenchymal-like cells, but not of PMVECs. Of note, knockdown of hypoxia-inducible factor $1 \alpha$ (HIF-1 $\alpha$ ) effectively inhibited hypoxic induction of $\alpha$-SMA, CollA 1 and the transcription factor Twist1, while rescuing hypoxic suppression of CD31; these results suggest that HIF-1 $\alpha$ is essential for hypoxia-induced EndMT and that it serves as an upstream regulator of Twist1. Mechanistically, HIF-1 $\alpha$ was identified to bind to the promoter of the Twist 1 gene, thus activating Twist1 transcription and regulating EndMT. Collectively, the present results indicate that the HIF-1 $\alpha /$ Twist1 pathway has a critical role in mediating the effect of hypoxia-induced EndMT in pulmonary arterial remodeling.
\end{abstract}

Correspondence to: Dr Zhi-Chao Li or Dr Bo Zhang, Department of Pathophysiology, Fourth Military Medical University, 169 Changle West Road, Xi'an, Shaanxi 710032, P.R. China

E-mail: lizhic@fmmu.edu.cn

E-mail: luckzb@fmmu.edu.cn

*Contributed equally

Key words: pulmonary hypertension, hypoxia, endothelialmesenchymal transition, hypoxia-induced factor, Twist1

\section{Introduction}

Chronic hypoxia is an important factor contributing to the near-irreversibility of hypoxia-induced pulmonary hypertension (HPH), a condition characterized by structural remodeling of small pulmonary arteries (PAs). These important morphological changes are characterized by an abnormal increase in numbers of smooth muscle (SM)-like cells [cells expressing $\alpha$-SM actin ( $\alpha$-SMA)] in the PA wall $(1,2)$, which results in thickening of muscular and elastic vessels, muscularization of distal vessels, and eventual development of pulmonary hypertension. The small pulmonary arteries and veins may be distinguished based on the relative abundance of SM cells or SM-like cells in vessel walls. However, the origin of SM-like cells has remained elusive.

Epithelial-mesenchymal transition (EMT) is a process wherein epithelial cells undergo phenotypic changes and develop into mesenchymal/SM-like cells (3). Similarly, endothelial cells may acquire a mesenchymal or SM-like phenotype, a process referred to as endothelial-mesenchymal transition (EndMT). Evidence of EndMT has been reported in the context of cardiac and vascular development, wound healing and various diseases, including fibrosis, diabetic nephropathy, heterotopic ossification and cancer (4-10). Transdifferentiated cells co-express the endothelial marker CD31 and the SM-like cell type marker $\alpha$-SMA. Thus, EndMT is regarded as another important mechanism for the generation of SM-like cells. The endothelial cell appears to be one of the targets in hypoxia, and endothelial cell dysfunction has a direct and indirect role in the process of pulmonary vascular remodelling (11). Ranchoux et al (12) reported that EndMT may be a source of $\alpha$-SMA-expressing cells. The EndMT participates in vascular remodeling as a characteristic of pulmonary hypertension; however, the underlying mechanism has remained to be fully elucidated.

Hypoxia-inducible transcription factor- $1 \alpha$ (HIF- $1 \alpha$ ) is a critical regulator of the cellular response to hypoxia. HIF-1 $\alpha$ activity in the endothelium of PAs has been observed to significantly increase in pulmonary hypertension (13). The HIF-1 $\alpha$-regulated gene Twist $(14,15)$ has an important role in EMT, cell movement and proliferation (16-18). However, the role of HIF-1 $\alpha /$ Twist in EndMT has remained to be fully characterized. In the present study, a significant upregulation of HIF-1 $\alpha$ in hypoxic pulmonary microvascular endothelial cells (PMVECs) was demonstrated, and knockdown of HIF-1 $\alpha$ 
and Twistl effectively blocked hypoxia-induced EndMT. It appeared that $\mathrm{HIF}-1 \alpha$ regulated the EndMT through binding to the promoter of the Twistl gene and subsequently activating Twist1 transcription and expression.

\section{Materials and methods}

Animal model. A total of 36 male Sprague Dawley rats (age, 6-8 weeks; weight, 200-250 g) were obtained from the Fourth Military Medical University. All experimental procedures were approved by the Animal Use and Care Committee for Research and Education of The Fourth Military Medical University (Xi'an, China). Control rats were housed under a 12-h light/dark cycle at room temperature (humidity: 50-60\%) and were provided water and a standard laboratory diet ad libitum. Rats were housed for 28 days in a chamber containing $10 \%$ oxygen for exposure to continuous hypobaric hypoxia. A gradual decrease in oxygen concentration was employed in order to acclimatize the rats to the hypoxic conditions (19). Over $30 \mathrm{~min}$, the pressure was slowly increased at the beginning of hypoxia by $0.5 \mathrm{~atm}$, and the oxygen concentration was reduced to $10 \%$. The gradual decrease in the oxygen concentration had no observable negative effect on the rats. After 4 weeks, the HPH models were successfully replicated. Rats in the normoxic group (control group) were housed continuously in room air ( $n=6$ per group). At the end of hypoxia exposure, the right ventricular systolic pressure (RVSP) and the ratio of ventricular weight [right ventricle/(left ventricle+septum), denoted as $\mathrm{RV} /(\mathrm{LV}+\mathrm{S})$ ] were measured. Increases in RVSP and $\mathrm{RV} /[\mathrm{LV}+\mathrm{S}]$ were considered as being indicative of $\mathrm{HPH}$.

Cell culture and chemical reagents. The lung was isolated from healthy adult rats under sterile conditions. After washing repeatedly with sterile D-Hank's buffer, tissues at the edge and surface of the lung (thickness, $\sim 1 \mathrm{~mm}$ ) were removed, dissected into small pieces and cultured in M200 medium (Gibco; Thermo Fisher Scientific, Inc., Waltham, MA, USA), supplemented with a growth factor cocktail [fibroblast growth factor, heparin, hydrocortisone and epidermal growth factor (Gibco; Thermo Fisher Scientific, Inc.)] and 20\% fetal bovine serum FBS (HyClone; GE Healthcare, Little Chalfont, UK). Primary cultures used were confirmed to be uncontaminated with SM cells by immunostaining for $\alpha$-SMA and CD31 or VIII factor. In the normoxic group, PMVECs were cultured at $37^{\circ} \mathrm{C}$ in a humidified atmosphere of $5 \% \mathrm{CO}_{2}$ in air. In the hypoxic groups, PMVECs were incubated in a hypoxic chamber containing $1 \% \mathrm{O}_{2}, 5 \% \mathrm{CO}_{2}$ and $94 \% \mathrm{~N}_{2}$ for 7 days, and SM-like cells were then obtained. In another experiment, PMVECs were also stimulated with transforming growth factor (TGF) $\beta$ (10 ng/ml) in normoxic conditions for 7 days. Antibodies against $\alpha$-SMA (MA1-744) were obtained from Thermo Fischer Scientific, Inc. (Waltham, MA, USA). Monoclonal antibodies against CD31 (ab64543) and Twist1 (ab50581) were purchased from Abcam (Cambridge, MA, USA). collagen (Col) 1A1 (sc-293182) and Col3A1 (sc-271249) were purchased from Santa Cruz Biotechnology, Inc. (Dallas, TX, USA). Anti-HIF-1 $\alpha$ monoclonal antibody (MAB5382) was purchased from EMD Millipore (Billerica, MA, USA). Secondary antibodies (anti-rabbit or anti-mouse IgG antibody conjugated to horseradish peroxidase; 7074 and 7076; 1:2,000) were purchased from Cell Signaling Technology (Danvers, MA, USA). Recombinant human TGF- $\beta$ was purchased from R\&D Systems (Minneapolis, MN, USA).

Immunofluorescence. Frozen tissue sections or cultured cells grown on coverslips were washed with PBS and fixed in $1 \%$ paraformaldehyde. Cells were subsequently permeabilized with $0.2 \%$ Triton X-100 in PBS at room temperature for $5 \mathrm{~min}$. The cells and tissue sections were blocked by $2 \%$ goat serum (OriGene Technologies, Beijing, China) at $37^{\circ} \mathrm{C}$ for $1 \mathrm{~h}$. Then they were incubated with primary antibodies (CD31, 1:500; $\alpha$-SMA, 1:1,000) overnight at $4^{\circ} \mathrm{C}$. Subsequently, samples were incubated with secondary antibody (Alexa Fluor ${ }^{\circledR} 594$ donkey anti-mouse IgG; R37115; 1:500; Molecular Probes; Thermo Fischer Scientific, Inc.) for $2 \mathrm{~h}$ at room temperature. Fluorescence was examined by confocal laser scanning microscopy.

Immunohistochemistry. Sagittal sections of the right lung were placed in $4 \%$ paraformaldehyde and processed for paraffin embedding. Sections $(5 \mu \mathrm{m})$ were prepared and mounted on glass slides prior to overnight incubation at $4^{\circ} \mathrm{C}$ with anti-Twist1 antibody (1:500). Slides were washed and incubated with corresponding secondary antibodies conjugated with alkaline phosphatase (Expose Rabbit specific HRP/DAB detection IHC kit; ab80437; Abcam). Sections were evaluated using an Olympus BX50 optical microscope (Olympus Corporation, Tokyo, Japan) equipped with an image analysis program (Image Pro Plus version 6.0; Media Cybernetics, Inc., Rockville, MD, USA).

Electron microscopy. Transmission electron microscopy (TEM) analysis was performed using glutaraldehyde-fixed PMVECs embedded in resin (Epon 812 epoxy resin). The clean slide was placed in $0.25 \%$ Formvar solution and then placed vertically on filter paper to air dry. Then the slide was exposed vertically to the surface of the water. The supporting membrane on the surface of the glass slide was removed and the 75-mesh copper grids placed on the membrane, removed from water and allowed to dry. Thin sections $(50-80 \mathrm{~nm})$ were collected on the formvar-coated copper grids and stained with $3 \%$ uranyl acetate and lead citrate solutions for 20-30 min respectively at room temperature. Following air drying at room temperature, the sections were examined under an electron microscope (JEM1200EX II; JEOL, Tokyo, Japan); images were captured.

Reverse transcription-quantitative polymerase chain reaction (RT-qPCR). Total RNA was extracted from lung tissues and PMVECs with TRIzol (Invitrogen; Thermo Fisher Scientific, Inc.) according to the manufacturer's instructions. Briefly, template RNA $(1 \mu \mathrm{g} / \mu \mathrm{l})$ was added to the individual tubes containing the master mix, using the Omniscript RT kit (Qiagen,Inc.). These were centrifuged briefly to collect residual liquid from the walls of the tubes, which were then incubated for $2 \mathrm{~h}$ at $37^{\circ} \mathrm{C}$. Then $2 \mu \mathrm{l}$ RNase A $(10 \mathrm{mg} / \mathrm{ml})$ was added and the reaction mix incubated for $10 \mathrm{~min}$ at $65^{\circ} \mathrm{C}, 5 \mathrm{~min}$ at $93^{\circ} \mathrm{C}$ and then cooled immediately on ice. RT-qPCR was performed with a MyiQ (Bio-Rad Laboratories, Inc., Hercules, CA, USA) using SYBR-Green I dye (Applied Biosystems; Thermo Fisher 
Table I. Primer sequences for real-time polymerase chain reaction.

\begin{tabular}{lll}
\hline Gene & \multicolumn{1}{c}{ Forward $\left(5^{\prime}-3^{\prime}\right)$} & Reverse $\left(5^{\prime}-3 '\right)$ \\
\hline$\alpha$-SMA & TTGTGGATCAGCGCCTTCAGTT & GACAGGCCAGGGCTAGAAGG \\
vWF & CCAACAGCCAGTCTCCCGTT & TGACGTAGGAGCAGTTGCCG \\
CD31 & TTCCGAGGGTGGCTTGAGTG & GAGGGAAGGCAATGGGGGTT \\
Vimentin & TGCAGTCACTCACCTGCGAA & CATTTCACGCATCTGGCGCT \\
Col1A1 & ATCACCAGACGCAGAAGTCATA & ACCAGGAGGACCAGGAAGTC \\
Col3A1 & GGAACAACTGATGGTGCTACTG & CCAAAATAAGAGGGGTGAAG \\
$\beta$-actin & ATCATGTTTGAGACCTTCAACA & CATCTCTTGCTCGAAGTCCA
\end{tabular}

SMA, smooth muscle actin; vWF, von Willebrand factor; Col, collagen.

Scientific, Inc.). Primer pairs used in the present study are listed in Table I. Each PCR was performed in a $50 \mu 1$ mixture containing $1 \mu \mathrm{l}$ cDNA, $5 \mu \mathrm{l}$ 10X Qiagen PCR buffer (Qiagen, Inc.), $10 \mu 15 \mathrm{X}$ Q-Solution (Qiagen, Inc.), $1 \mu \mathrm{l}$ each of deoxynucleotide triphosphate mix (10 mM), $0.1 \mu \mathrm{M}$ of each sense and antisense primer and $0.5 \mu 1$ Taq DNA polymerase (Qiagen, Inc.), by using the Taq DNA Polymerase kit (Qiagen, Inc.). The amplification reaction consisted of initial denaturation at $95^{\circ} \mathrm{C}$ for $2 \mathrm{~min}$, followed by three-step cycling that consisted of denaturation at $95^{\circ} \mathrm{C}$ for $10 \mathrm{sec}$, annealing at $60^{\circ} \mathrm{C}$ for $30 \mathrm{sec}$ and extension at $70^{\circ} \mathrm{C}$ for $30 \mathrm{sec}$ for 30 cycles. The comparative threshold cycle $(\mathrm{Cq})$ method was employed for quantification of transcripts (20).

Western blot assay. Lung tissues and cultured PMVECs were placed in lysis buffer $(50 \mathrm{mM} \mathrm{NaCl}, 50 \mathrm{mM} \mathrm{NaF}$, $50 \mathrm{mM}$ sodium pyrophosphate, $5 \mathrm{mM}$ EDTA, $5 \mathrm{mM}$ EGTA, $2 \mathrm{mM} \mathrm{Na} \mathrm{VO}_{4}, 0.5 \mathrm{mM}$ phenylmethylsulfonyl fluoride and $10 \mathrm{mM}$ 4-(2-hydroxyethyl)-1-piperazineethanesulfonic acid at $\mathrm{pH} 7.4$, together with $0.1 \%$ Triton X-100, $10 \mathrm{mg} / \mathrm{l}$ leupeptin and $5 \%$ aprotinin) respectively. Protein concentrations were determined with the bicinchoninic acid protein assay. Equivalent amounts of protein $(50 \mu \mathrm{g})$ were subjected to $10 \%$ SDS-PAGE and transferred onto a nitrocellulose membrane (Bio-Rad Laboratories). Membranes were blocked overnight at $4^{\circ} \mathrm{C}$ with PBS containing 5\% non-fat dry milk and $0.1 \%$ Tween-20. Following blocking, membranes were incubated overnight at $4^{\circ} \mathrm{C}$ with primary antibodies, including anti-HIF-1 $\alpha$ (1:500), anti-CD31 (1:500), anti-Twist1 (1:500), anti- $\alpha$-SMA (1:1,000), anti-vimentin (ab92547; $1: 200)$ and anti- $\beta$-actin (A2228; 1:4,000; Sigma-Aldrich; Merck KGaA). Proteins were incubated with secondary antibodies (anti-rabbit or anti-mouse IgG antibody; Cat. 7074 and Cat. 7076; 1:2,000; Cell Signaling Technology) for $1 \mathrm{~h}$ at $37^{\circ} \mathrm{C}$ in PBS containing $1 \%$ non-fat dry milk and $0.1 \%$ Tween-20. The chemiluminescence signal was detected using enhanced chemiluminescent substrate (SuperSignal $^{\mathrm{TM}}$ West Femto Trial Kit, Thermo Fisher Scientific, Inc.).

Cell transfection. Primary PMVECs were transduced with lentiviral vector containing small interfering (si)RNA targeting either rat HIF-1 $\alpha$ or Twist1 (Genechemgene, Shanghai, China). For transduction, cells were seeded in 6-well plates at a density of $5 \times 10^{5}$ cells per well. Virus particles were added at a multiplicity of infection of 40, followed by incubation for $36 \mathrm{~h}$. Cells were then washed and incubated at $37^{\circ} \mathrm{C}$ for $60 \mathrm{~h}$ prior to PCR and western blot analysis. The sequences of Twist 1 siRNA and HIF-1 $\alpha$ siRNA were 5'-GGCGGCCAGGTACATCGACTT-3' and 5'-AACCAGTTGAATCTTCAGATA-3', respectively. The sequences of negative control was TTCTCCGAACGTGTC ACGT.

Cell proliferation. PMVECs or hypoxia-induced SM-like cells were seeded on to 96-well plates and incubated for 24 and $48 \mathrm{~h}$ under normoxic or hypoxic conditions. Subsequently, $10 \mu \mathrm{l}$ MTT solution $(5 \mathrm{mg} / \mathrm{ml})$ was added into each well and following $4 \mathrm{~h}$ of incubation the supernatant was gently removed by a pipette and discarded, and $150 \mu \mathrm{l}$ dimethyl sulfoxide added. The optical density values were detected at a wavelength of $490 \mathrm{~nm}$ using a spectrophotometer (Bio-Tek Power Wave XS, Bio-Tek, Winooski, VT, USA).

Wound healing assay. PMVECs and SM-like cells were grown to confluence. A linear wound was made by scraping the cell layer with a $0.5 \mathrm{ml}$ plastic Pasteur pipette. Following two washes with culture medium to remove the detached cells and debris, the cells were exposed to normoxic or hypoxic conditions for 24 and $48 \mathrm{~h}$, and the size of the wounds was measured.

Chromatin immunoprecipitation (ChIP). The ChIP assay was performed using the EZ-Zyme ${ }^{\mathrm{TM}}$ Chromatin Prep Kit (EMD Millipore) according to the manufacturer's instructions. In brief, cell lysates were incubated with $1 \mu \mathrm{g}$ RNA polymerase II, IgG (1 $\mu \mathrm{g} / \mathrm{ml}$; Wanleibio Co., Ltd., Shenyang, China) or anti-HIF-1 $\alpha$ antibody (1:500). The immunoprecipitated DNA was amplified using Twistl promoter-specific primers (21). PCR generated a 196-bp product from the regulatory region of the Twist1 promoter containing CCACGTGG. Primers for Twistl were as follows: Forward 5'-TCGGATGAA AGCACAGTCG-3' and reverse 5'-GCCACCGACTTCCTG AGA-3'.

Statistical analysis. All values are expressed as the mean \pm standard error of the mean. Statistical analysis was performed using analysis of variance and multiple 


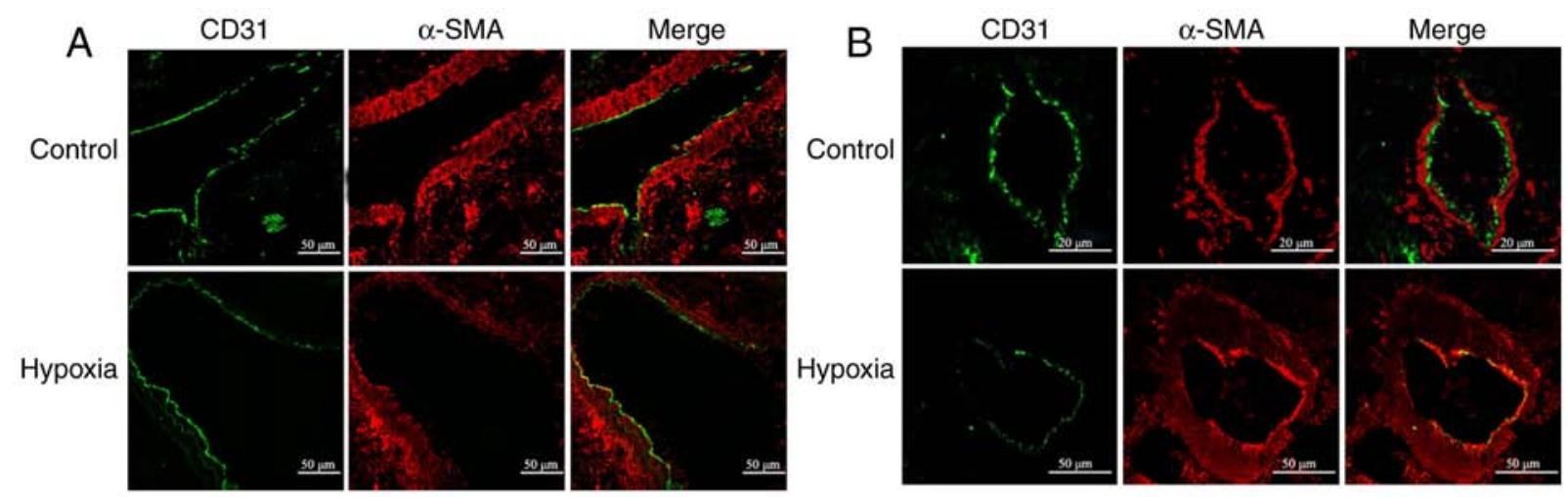

Figure 1. Endothelial-mesenchymal transition was observed in PAs of rat models of HPH. Confocal microscopy images displaying immunofluorescent staining of the (A) larger proximal and (B) distal PA in frozen lung sections from control or HPH rats. Endothelial cells were detected using anti-CD31 antibody (green). Immunostaining of smooth muscle-like cells was performed using an antibody against $\alpha$-SMA (red). Sections were counterstained with DAPI (blue). Only small amounts of smooth muscle-like cell marker were detected in the intimal layer of larger PA from the merged image, but obvious co-localization of CD31 and $\alpha$-SMA expression was observed in the small PAs following hypoxic exposure (scale bar, 20 or $50 \mu \mathrm{m}$ ). SMA, smooth muscle actin; HPH, hypoxia-induced pulmonary hypertension; PA, pulmonary artery.

comparisons were made by Tukey's method. Statistical analysis was processed by SPSS version 16.0 (SPSS, Inc., Chicago, IL, USA). Differences were considered to be statistically significant at $\mathrm{P}<0.05$.

\section{Results}

Hypoxia induces transdifferentiation of endothelial cells into SM-like cells in small, but not in large PAs. A rat model of chronic HPH was used to examine the effect of hypoxia on EndMT in vivo. In large proximal PAs, hypoxia did not appear to alter the expression of endothelial marker CD31 and mesenchymal marker $\alpha$-SMA (Fig. 1A). By contrast, a considerable downregulation of CD31 along with significant upregulation of $\alpha$-SMA was observed in small distal PAs (Fig. 1B). In addition, hypoxia led to PA remodeling, as evidenced by the appreciable intimal thickening (Fig. 1B). Of note, CD31 was co-localized with $\alpha$-SMA (Fig. 1B), which suggested transdifferentiation of endothelial cells into $\alpha$-SMA-expressing mesenchymal-like cells (SM-like cells). These results indicate that HPH is associated with remodeling of small PAs and that hypoxia may induce EndMT in vivo.

Hypoxia induces transdifferentiation of endothelial cells into SM-like cells in vitro. Next, the present study sought to determine the role of hypoxia in EndMT in vitro. As presented in Fig. 2, Weibel-Palade bodies, as well as abundant pinocytotic vesicles near the plasma membrane, were observed in the cytoplasm of normal PMVECs, while $\alpha$-SMA stress fibers were undetectable, which is a typical phenotype of endothelial cells. However, following hypoxic exposure, mixed cell populations were observed in PMVECs. Certain cells exhibited well-developed endoplasmic reticulum whose cisternae were expanded, and increased protein secretion and abundant VEC-specific pinocytotic vesicles were present in the cytoplasm (Fig. 2B), whereas other cells exhibited SM-like features, including aggregation of $\alpha$-SMA filaments in the cytoplasm and presence of dense bodies abutting the cell membrane (Fig. 2C). Pinocytotic vesicles were not observed in these cells (Fig. 2C). These results suggest that hypoxic
PMVECs undergo a transition from endothelial cells to SM-like cells.

To further confirm the role of hypoxia in EndMT in vitro, endothelial and mesenchymal markers were examined in hypoxic PMVECs. The results indicated that 7 days of hypoxia exposure attenuated the protein expression of CD31, but markedly enhanced the expression of $\alpha$-SMA and the mesenchymal markers Col1A1 and Col3A1 (Fig. 3A). This effect was comparable to that of TGF- $\beta$, a known potent inducer of EndMT. The mRNA expression of these markers exhibited a similar trend (Fig. 3B). These results suggest that the effect of hypoxia in inducing EndMT was akin to that of TGF- $\beta$.

Increased cell proliferation and migration are important features associated with EndMT. Therefore, the degree of proliferation and migration of PMVECs and SM-like cells after EndMT under hypoxic conditions was detected. As presented in Fig. 4A and B, PMVECs did not exhibit any proliferation and migration potential under hypoxia over $48 \mathrm{~h}$. Conversely, SM-like cells exhibited time-dependent proliferation and migration under hypoxia. As the SM-like cells were derived from the PMVECs incubated in hypoxia over 7 days, these results demonstrate that hypoxia induces EndMT, resulting in a phenotype with increased cell proliferation and migration.

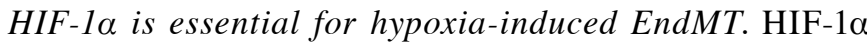
is known to be a master regulator of the hypoxic response. Therefore, the present study examined the role of HIF-1 $\alpha$ in hypoxia-induced EndMT. The present results indicated that hypoxia induced the expression of HIF-1 $\alpha$ (Fig. 5A). Upregulation of Twist1 expression was also detected in the small PA specimens from HPH rats (Fig. 6). Of note, knockdown of HIF-1 $\alpha$ effectively inhibited 7 days of hypoxia exposure-induced expression of Twist1, $\alpha$-SMA and Col1A1, while reversing hypoxia-induced suppression of CD31 expression (Fig. 5). These results indicate that HIF-1 $\alpha$ has an essential role in hypoxia-induced EndMT and that it may act as an upstream regulator of Twist1.

Twistl is important in hypoxia-induced EndMT. Since hypoxia also upregulates Twist1, the present study next sought 


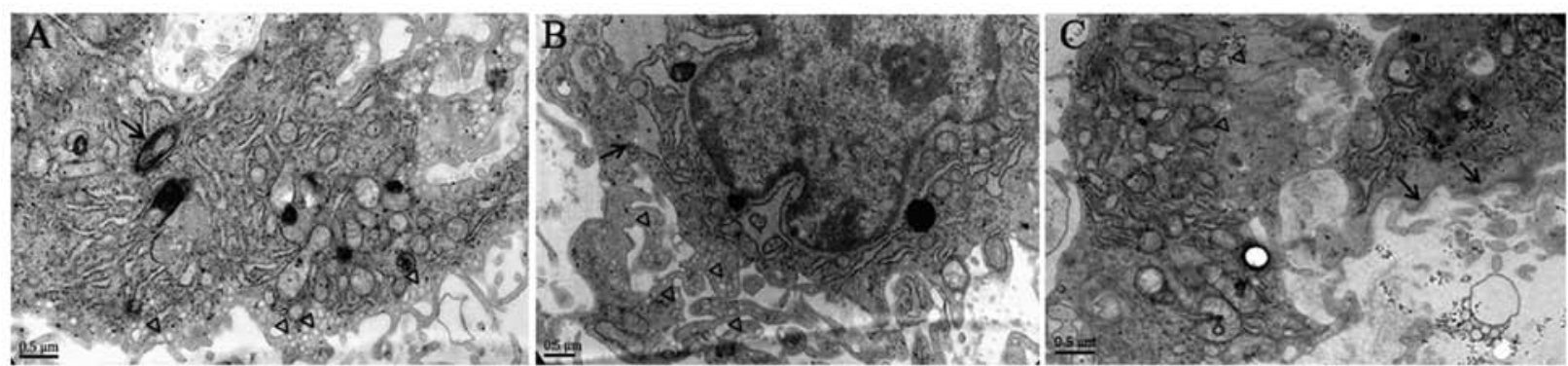

Figure 2. Transmission electron micrographs of normoxia- and hypoxia-treated PMVECs. (A) Normal PMVECs exhibited abundant pinocytotic vesicles near the plasma membrane (triangles) and Weibel-Palade bodies (arrows) in the cytoplasm. (B) Hypoxia-induced cells displayed a mixed phenotype. Well-developed endoplasmic reticulum was present, whose cisternae were expanded, and increased protein secretion (arrow) as well as abundant vascular endothelial cell-specific pinocytotic vesicles (triangles) were present in the cytoplasm. (C) PMVECs cultured under hypoxic conditions exhibited typical features of smooth muscle cells, including the aggregation of intermediate filaments (triangles) in the cytoplasm and dense bodies (arrows) close to the cell membrane (scale bar, $0.5 \mu \mathrm{m}$ ). PMVECs, pulmonary microvascular endothelial cells.

A

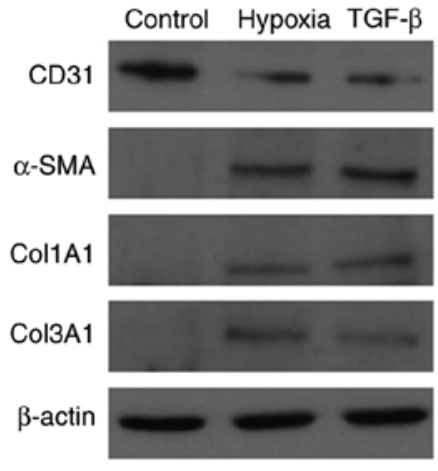

B

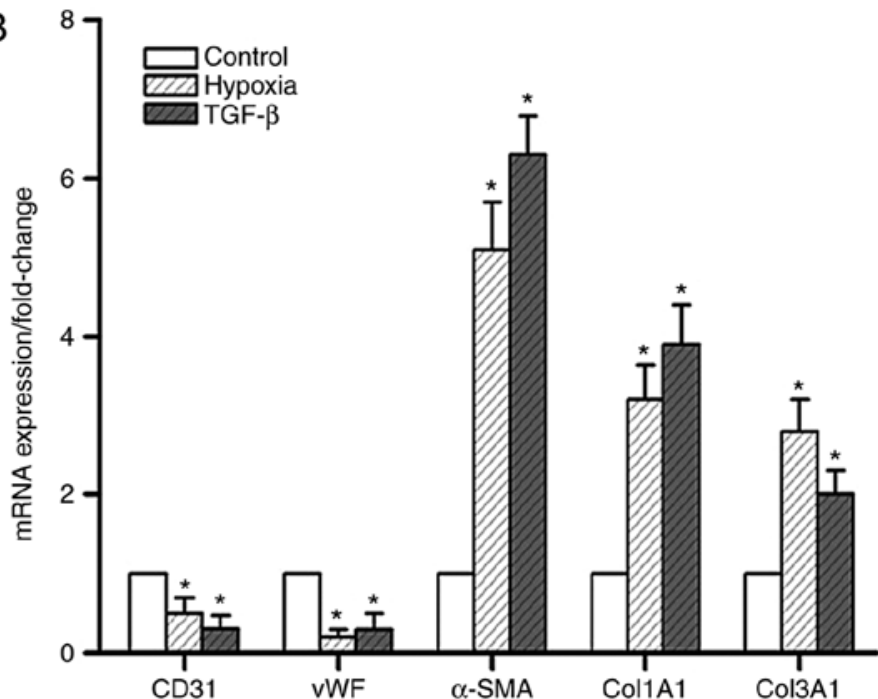

Figure 3. Expression of endothelial and smooth muscle-like cell markers in pulmonary microvascular endothelial cells. (A) Effects of hypoxia and TGF- $\beta$ on the expression of endothelial and smooth muscle-like cell markers. Western blot analysis demonstrated that hypoxia and TGF- $\beta$ obviously decreased CD31 expression and increased $\alpha$-SMA, Col1 A1 and Col3A1 expression. (B) Expression of endothelial and smooth muscle-like cell markers was measured by reverse transcription-quantitative polymerase chain reaction analysis prior to and after hypoxic exposure and TGF- $\beta$ treatment. A marked upregulation of $\alpha$-SMA, Col1A1 and Col3A1 expression was noted following hypoxic exposure. Values are expressed as the mean \pm standard error of the mean $(\mathrm{n}=6)$. ${ }^{*} \mathrm{P}<0.05 \mathrm{vs}$. control. TGF, transforming growth factor; SMA, smooth muscle actin; Col, collagen; vWF, von Willebrand factor.
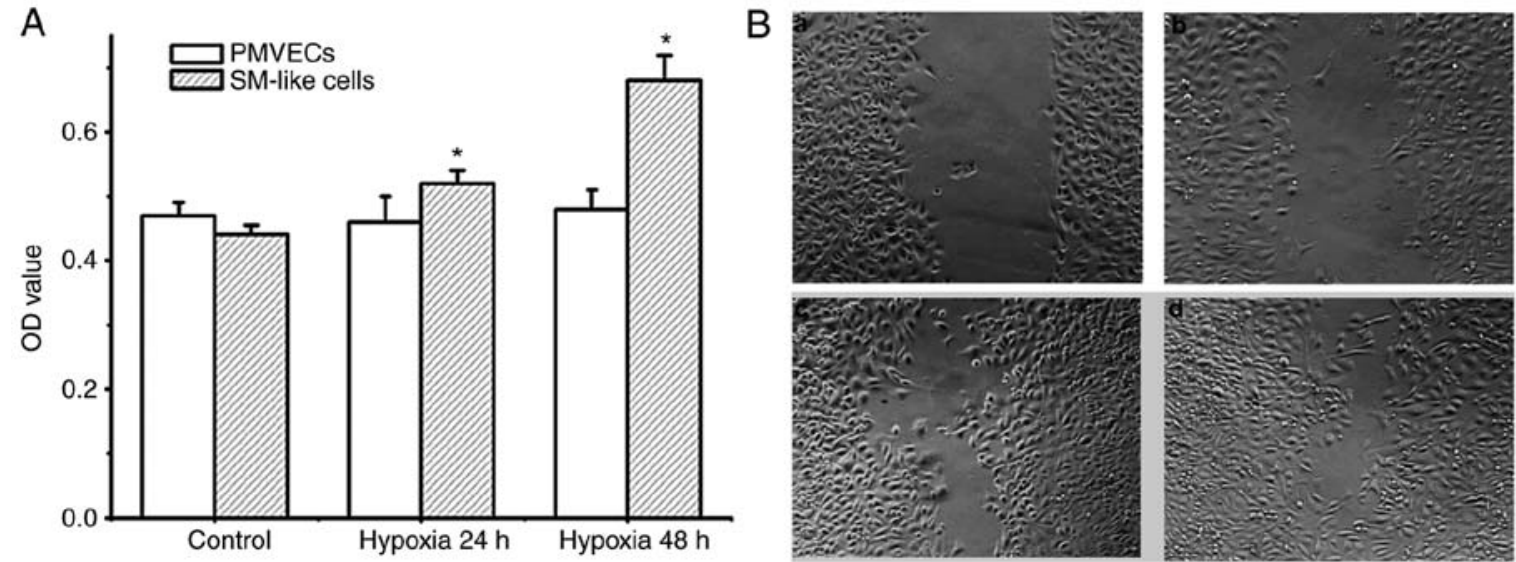

Figure 4. Cell proliferation and migration following hypoxic exposure. (A) Proliferation of PMVECs and SM-like cells was measured by an MTT assay. The results indicated that hypoxia induced proliferation of SM-like cells but not of PMVECs. Values are expressed as the mean \pm standard error of the mean ( $\mathrm{n}=6$ ). ${ }^{\text {"P }}<0.05$ vs. control. (B) Migration of PMVECs and SM-like cell was measured by a wound-healing assay. (a) Treatment of PMVECs with hypoxia for 24 h; (b) treatment of PMVECs with hypoxia for $48 \mathrm{~h}$; (c) treatment of SM-like cells with hypoxia for $24 \mathrm{~h}$; and (d) treatment of SM-like cells with hypoxia for $48 \mathrm{~h}$. Hypoxia facilitated the migration of SM-like cells. SM, smooth muscle; PMVECs, pulmonary microvascular endothelial cells; OD, optical density. 

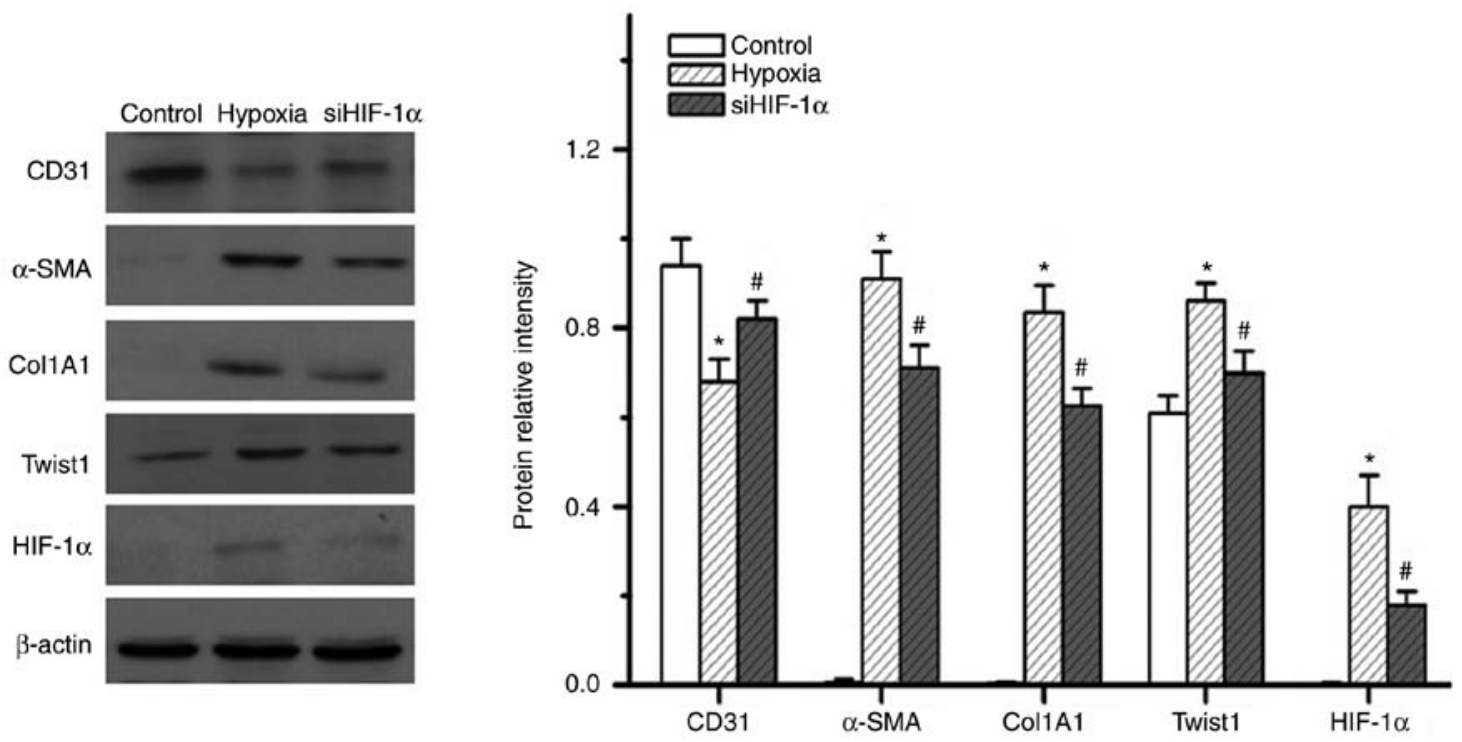

Figure 5. Effect of HIF-1 $\alpha$ inhibition on the expression of endothelial and smooth muscle-like cell markers in pulmonary microvascular endothelial cells. Western blot analysis demonstrated that siHIF-1 $\alpha$ markedly increased CD31 expression and decreased $\alpha$-SMA, Col1A1, Twist1 and HIF-1 $\alpha$ expression upon hypoxic exposure. " $\mathrm{P}<0.05$ vs. control; ${ }^{~} \mathrm{P}<0.05$ vs. hypoxia group. SMA, smooth muscle actin; Col, collagen; HIF, hypoxia-inducible factor; siHIF-1 $\alpha$, small interfering RNA targeting HIF-1 $\alpha$.
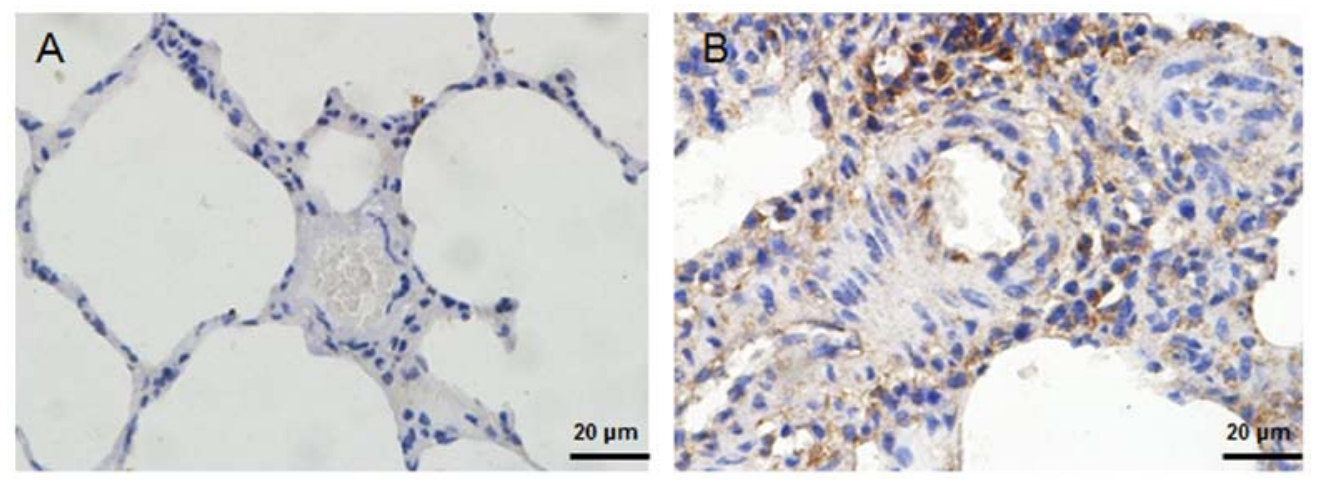

Figure 6. Immunhistochemical analysis of Twist1 in rat lungs. Immunostaining with an antibody to Twist1 in (A) lungs of rats kept under normoxic conditions compared with (B) lungs from hypoxic rats (scale bar, $20 \mu \mathrm{m}$ ). Positive staining was indicated by a brown color. The results indicated that Twist1 staining was enhanced in hypoxic lung sections.
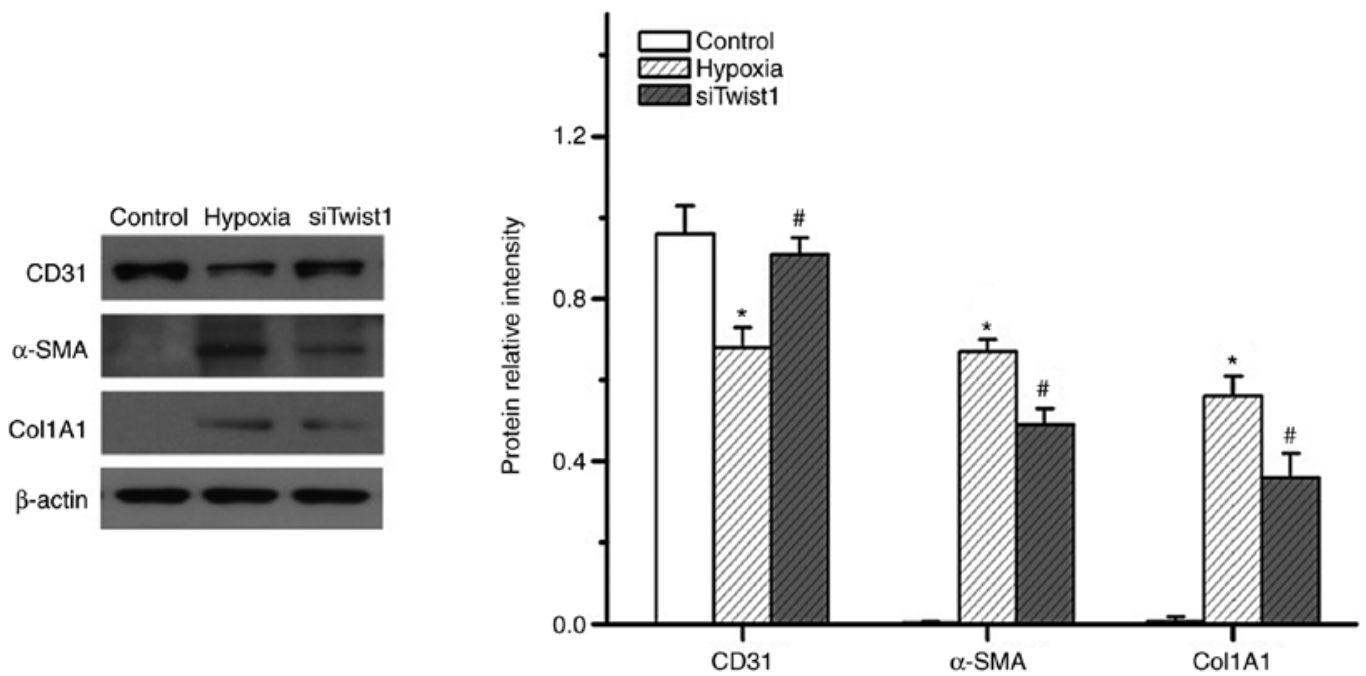

Figure 7. Effect of Twist inhibition on expression of endothelial and smooth muscle-like cell markers in pulmonary microvascular endothelial cells. Western blot analysis demonstrated that siTwist1 obviously increased CD31 expression and decreased $\alpha$-SMA and Col1A1 expression upon hypoxic exposure. ${ }^{*} \mathrm{P}<0.05$ vs. control; " $\mathrm{P}<0.05$ vs. hypoxia group. SMA, smooth muscle actin; Col, collagen; siTwist1, small interfering RNA targeting Twist1. 


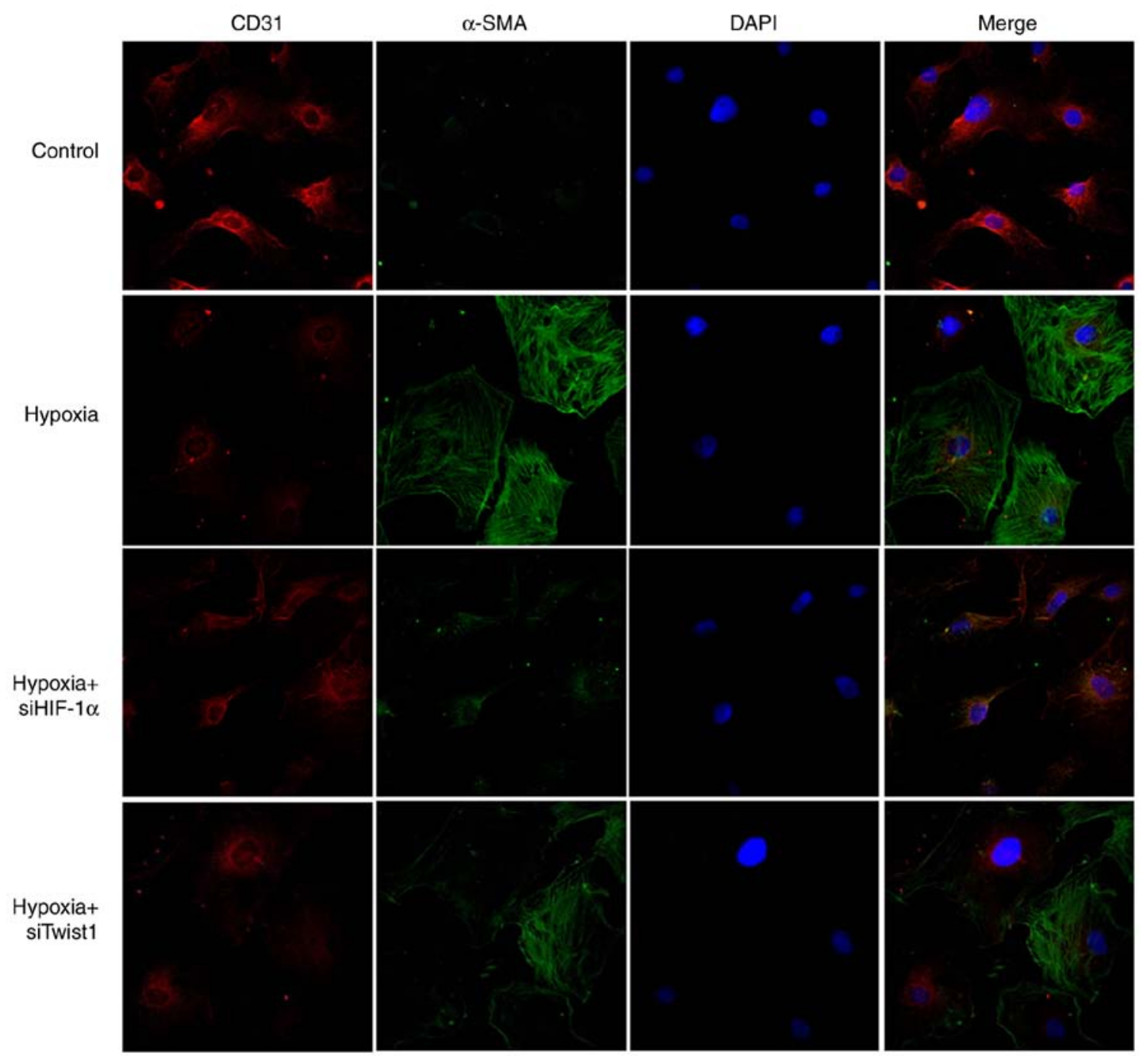

Figure 8. Hypoxia-induced PMVECs express endothelial and SM-like cell markers in vitro. Double immunofluorescent staining for CD31 (red) and $\alpha$-SMA (green) was performed on PMVECs. Cells were counterstained with DAPI (blue). (magnification, $\mathrm{x} 400$ by confocal microscopy). PMVECs were positive for CD31 but negative for $\alpha$-SMA expression. PMVECs acquired an elongated, SM-like morphology when incubated under hypoxic conditions for 7 days. Certain cells expressed lower levels of endothelial markers CD31 but large amounts of $\alpha$-SMA. siHIF-1 $\alpha$ or siTwist1 inhibited the endothelial-mesenchymal transition process. PMVECs, pulmonary microvascular endothelial cells; SMA, smooth muscle actin; siHIF-1 $\alpha$, small interfering RNA targeting hypoxia-inducible factor-1 $\alpha$.

to determine the function of Twist1 in hypoxia-induced EndMT. Similar to HIF-1 $\alpha$, knockdown of Twist1 also altered the expression of CD31, $\alpha$-SMA and Col1A1 in hypoxic PMVECs (Fig. 7). The knockdown efficiency of the siRNAs was $80-85 \%$. It appeared that knockdown of HIF-1 $\alpha$ exerted a more obvious effect on hypoxia-induced PMVEC transdifferentiation to mesenchymal-like cells than that of Twist1. This was evidenced in the obviously greater inhibition of hypoxia-induced $\alpha$-SMA expression by knockdown of HIF-1 $\alpha$, as compared with the effect of Twist1 knockdown (Fig. 8). This observation is consistent with the hypothesis that HIF-1 $\alpha$ is an upstream regulator of Twist1. These results suggest that Twist1 may be a mediator of hypoxia/HIF-1 $\alpha$-induced EndMT in vitro.

HIF-1 $\alpha$ binds with the promoter of the Twistl gene. The present study then investigated the mechanism by which HIF-1 $\alpha$ regulates Twist1.An 8-bp HIF-1 $\alpha$-binding sequence (CCACGTGG) located between 321 and 328 bp upstream of the first exon of

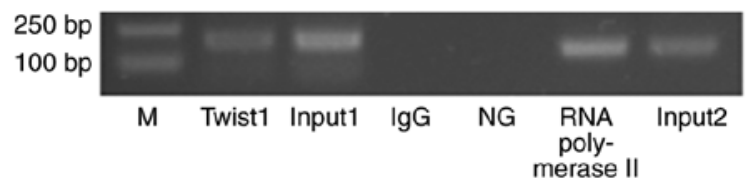

Figure 9. HIF-1 $\alpha$-Twist1 interaction. Chromatin immunoprecipitation assay results demonstrated the existence of HIF-binding sites in the Twist1 promoter, indicating that Twist1 is an HIF-regulated gene. HIF, hypoxia-inducible factor; IgG, immunoglobulin G; M, marker; NG, negative control.

the Twist1 transcript was identified using JASPAR database (http://jaspar2016.genereg.net/). A ChIP assay was performed to determine whether HIF-1 $\alpha$ indeed binds to this site. As presented in Fig. 9, HIF-1 $\alpha$ physically interacted with the binding sequence of the Twist1 promoter in PMVECs, which suggests that HIF-1 $\alpha$ regulates Twist1 expression by binding to the Twist1 promoter, and that the HIF-1 $\alpha$-Twist1 axis is an important pathway in hypoxia-induced EndMT. 


\section{Discussion}

The present study indicated that endothelial cells in the pulmonary vasculature differentiate towards an SM phenotype via EndM transdifferentiation upon exposure to hypoxia. The endothelium may be a potential source of SM cells in the vascular system, and the HIF-1 $\alpha$-Twist1 intracellular signaling pathway is involved in this process.

Increased expression of $\alpha$-SMA was observed in the walls of small PAs in response to chronic exposure to hypoxia. These SM-like cells not only lead to abnormal vasoconstriction, but also have the ability to proliferate, migrate and produce extracellular matrix, which contributes to structural remodeling and results in pulmonary hypertension. These SM-like cells are thought to be derived from the proliferation of resident vascular SM cells, an SM-like subpopulation residing within the media (22) or from adventitial fibroblasts (23). Several studies have indicated that circulating progenitor cells and resident vascular progenitor cells may acquire an SM-like phenotype at the site of vascular injury $(19,24)$. However, endothelial cells were observed to retain the capacity to transition into mesenchymal or SM-like cells in vitro. With TGF- $\beta$ treatment, isolated endothelial cells from the bovine aorta were previously reported to convert to spindle-shaped $\alpha$-SMA-expressing cells (25). Zhu et al (26) reported that hypoxia induced transdifferentiation of endothelial cells into SM-like cells and that this process was regulated by myocardin. Similarly, Ranchoux et al (12) reported that EndMT may be a source of those $\alpha$-SMA-expressing cells. EndMT participates in vascular remodeling associated with pulmonary hypertension. In the present study, cells with expression of $\alpha$-SMA were not observed in the intimal layer of large proximal PA specimens from HPH rats, although certain $\alpha$-SMA-expressing cells were observed in distal PA specimens. Pulmonary hypertension is characterized by cellular changes in the walls of PAs. These changes include the appearance of SM-like cells in previously non-muscularized vessels, and medial and adventitial thickening of the muscular and elastic vessels. In addition, intimal changes have been consistently observed in rat models of $\mathrm{HPH}$; however, these intimal changes are typically minimal, at least from a morphological point of view (27). The magnitude of the changes depends on the species studied for exposure to hypoxia. Since it is hard to morphologically distinguish between small pulmonary arteries and veins, small circular vessels that had a greater expression of SM cells than pulmonary arteries were selected for analysis in the present study. In vitro, it was observed that hypoxia induced transdifferentiation of PMVECs into SM-like cells. Therefore, endothelium appears to be a source of SM-like cells.

Next, the present study explored whether HIF-1 $\alpha$ may modulate the transdifferentiation of endothelial cells. HIF-1 $1 \alpha$ is a transcriptional regulator that has an important role in the cellular response to hypoxia. In addition, animals deficient in HIF-1 $\alpha$ have attenuated HPH (28). HIF-1 $\alpha$ transcriptionally controls a diverse number of genes, including those involved in vascular remodeling. Higgins et al (29) reported that hypoxia promotes fibrogenesis through HIF- $1 \alpha$-mediated stimulation of EMT. As an HIF-1 $\alpha$-regulated gene, Twist, a basic helix-loop-helix transcription factor, was identified as a crucial factor in the EMT $(30,31)$. Ranchoux et al (12) reported that EndMT involves neoexpression of Twist1. Sun et al (32) reported that Twist promoters contain HIF-1 $\alpha$-binding sites, that HIF-1 $\alpha$ induces Twist expression in hypoxic tubular cells, and that this has a role in the EMT during renal fibrogenesis. In the present study, when siRNA was used to block the expression of HIF-1 $\alpha$, hypoxia-induced $\alpha$-SMA expression was markedly suppressed in PMVECs. Knockdown of HIF-1 $\alpha$ also resulted in a marked inhibition of Twist1 expression induced by hypoxia. When Twist 1 was knocked down by siRNA, the expression of CD31, $\alpha$-SMA and Col1A1 was also altered in hypoxic PMVECs, and hypoxia-induced EndMT was effectively inhibited. This indicates that Twist1 also mediates hypoxia-induced EndMT in PMVECs, and that HIF-1 $\alpha$ is an upstream regulator of Twist1. The process of EndMT is therefore likely to be in part regulated by HIF-1 $\alpha$-Twist1. In addition, the Twist1 gene promoter was identified to contain HIF-1 $\alpha$-binding sites, and that HIF- $1 \alpha$ induces Twist1 expression in PMVECs, further confirming this interaction.

Although HPH is an important subtype of pulmonary hypertension and has the features of pulmonary hypertension, hypoxia is not defined as the major etiological factor. Thus, the HPH model used in the present study may not entirely replicate the actual pathogenesis of pulmonary hypertension. To better understand the precise molecular mechanisms involved in the pathogenesis of pulmonary hypertension, other factors, including inflammation, should also be taken into consideration.

In conclusion, the present study provides evidence of the EndMT process taking place in pulmonary vascular remodeling under chronic hypoxic conditions. The HIF- $1 \alpha$-Twist1 pathway was also suggested to be involved in EndMT. These observations may help explain the appearance of SM-like cells in the intima of PAs in HPH. Identification of EndMT in PAs and elucidation of associated signaling pathways will confer novel insight into the pathogenesis of pulmonary hypertension.

\section{Acknowledgements}

Not applicable.

\section{Funding}

This study was supported by the National Natural Science Foundation of China (nos. 81571839, 81000017 and 81471816).

\section{Availability of data and materials}

The datasets used and/or analyzed during the current study are available from the corresponding author on reasonable request.

\section{Authors' contributions}

BZ was mainly responsible for the design of the experiment, establishing animal model, statistical analysis and the writing of the article. WN was responsible for immunofluorescence, immunohistochemistry and electron microscopy assay. H-YD was responsible for RT-qPCR and western blot assay. M-LL was responsible for cell transfection, proliferation and wound healing assay. YL was responsible for ChIP assay. Z-CL was responsible for the design of the experiment. 


\section{Ethical approval and consent to participate}

All experimental procedures on animals were approved by the Animal Use and Care Committee for Research and Education of The Fourth Military Medical University (Xi'an, China).

\section{Consent for publication}

Not applicable.

\section{Competing interests}

The authors declare that they have no competing interests.

\section{References}

1. Morrell NW, Adnot S, Archer SL, Dupuis J, Jones PL, MacLean MR, McMurtry IF, Stenmark KR, Thistlethwaite PA, Weissmann N, et al: Cellular and molecular basis of pulmonary arterial hypertension. J Am Coll Cardiol 54 (1 Suppl): S20-S31, 2009.

2. Stenmark KR, Fagan KA and Frid MG: Hypoxia-induced pulmonary vascular remodeling: Cellular and molecular mechanisms. Circ Res 99: 675-691, 2006.

3. Hay ED: An overview of epithelio-mesenchymal transformation. Acta Anat 154: 8-20, 1995.

4. Arciniegas E, Neves CY, Carrillo LM, Zambrano EA and Ramirez R: Endothelial-mesenchymal transition occurs during embryonic pulmonary artery development. Endothelium 12: 193-200, 2005

5. Armstrong EJ and Bischoff J: Heart valve development: Endothelial cell signaling and differentiation. Circ Res 95: 459-470, 2004.

6. Hashimoto $\mathrm{N}$, Phan SH, Imaizumi K, Matsuo $\mathrm{M}$, Nakashima H, Kawabe T, Shimokata K and Hasegawa Y: Endothelial-mesenchymal transition in bleomycin-induced pulmonary fibrosis. Am J Respir Cell Mol Biol 43: 161-172, 2010.

7. Li J, Qu X, Yao J, Caruana G, Ricardo SD, Yamamoto Y, Yamamoto H and Bertram JF: Blockade of endothelial-mesenchymal transition by a Smad3 inhibitor delays the early development of streptozotocin-induced diabetic nephropathy. Diabetes 59: 2612-2624, 2010.

8. Liebner S, Cattelino A, Gallini R, Rudini N, Iurlaro M, Piccolo S and Dejana E: Beta-catenin is required for endothelial-mesenchymal transformation during heart cushion development in the mouse. J Cell Biol 166: 359-367, 2004.

9. Potenta S, Zeisberg E and Kalluri R: The role of endothelial-to-mesenchymal transition in cancer progression. $\mathrm{Br} \mathrm{J}$ Cancer 99: 1375-1379, 2008.

10. Zeisberg EM, Tarnavski O, Zeisberg M, Dorfman AL, McMullen JR, Gustafsson E, Chandraker A, Yuan X, Pu WT, Roberts AB, et al: Endothelial-to-mesenchymal transition contributes to cardiac fibrosis. Nat Med 13: 952-961, 2007.

11. Humbert M, Montani D, Perros F, Dorfmüller P, Adnot S and Eddahibi S: Endothelial cell dysfunction and cross talk between endothelium and smooth muscle cells in pulmonary arterial hypertension. Vascul Pharmacol 49: 113-118, 2008.

12. Ranchoux B, Antigny F, Rucker-Martin C, Hautefort A, Péchoux C, Bogaard HJ, Dorfmüller P, Remy S, Lecerf F, Planté S, et al: Endothelial-to-mesenchymal transition in pulmonary hypertension. Circulation 131: 1006-1018, 2015.

13. Wojciak-Stothard B, Tsang LY and Haworth SG: Rac and Rho play opposing roles in the regulation of hypoxia/reoxygenation-induced permeability changes in pulmonary artery endothelial cells. Am J Physiol Lung Cell Mol Physiol 288: L749-L760, 2005.

14. Yang MH and Wu KJ: TWIST activation by hypoxia inducible factor-1 (HIF-1): Implications in metastasis and development. Cell Cycle 7: 2090-2096, 2008.

15. Yang MH, Wu MZ, Chiou SH, Chen PM, Chang SY, Liu CJ, Teng SC and Wu KJ: Direct regulation of TWIST by HIF-1alpha promotes metastasis. Nat Cell Biol 10: 295-305, 2008.
16. Desprez PY, Sumida T and Coppe JP: Helix-loop-helix proteins in mammary gland development and breast cancer. J Mammary Gland Biol Neoplasia 8: 225-239, 2003.

17. Lo HW, Hsu SC, Xia W, Cao X, Shih JY, Wei Y, Abbruzzese JL, Hortobagyi GN and Hung MC: Epidermal growth factor receptor cooperates with signal transducer and activator of transcription 3 to induce epithelial-mesenchymal transition in cancer cells via up-regulation of TWIST gene expression. Cancer Res 67: 9066-9076, 2007.

18. Pozharskaya V, Torres-Gonzalez E, Rojas M, Gal A, Amin M, Dollard S, Roman J, Stecenko AA and Mora AL: Twist: A regulator of epithelial-mesenchymal transition in lung fibrosis. PLoS One 4: e7559, 2009.

19. Frid MG, Brunetti JA, Burke DL, Carpenter TC, Davie NJ, Reeves JT, Roedersheimer MT, van Rooijen N and Stenmark KR: Hypoxia-induced pulmonary vascular remodeling requires recruitment of circulating mesenchymal precursors of a monocyte/macrophage lineage. Am J Pathol 168: 659-669, 2006.

20. Livak KJ and Schmittgen TD: Analysis of relative gene expression data using real-time quantitative PCR and the $2^{-\Delta \Delta C_{\mathrm{T}}}$ method. Methods 25: 402-408, 2001.

21. Spencer VA, Sun JM, Li L and Davie JR: Chromatin immunoprecipitation: A tool for studying histone acetylation and transcription factor binding. Methods 31: 67-75, 2003.

22. Wohrley JD, Frid MG, Moiseeva EP, Orton EC, Belknap JK and Stenmark KR: Hypoxia selectively induces proliferation in a specific subpopulation of smooth muscle cells in the bovine neonatal pulmonary arterial media. J Clin Invest 96: 273-281, 1995.

23. Arciniegas E, Frid MG, Douglas IS and Stenmark KR: Perspectives on endothelial-to-mesenchymal transition: Potential contribution to vascular remodeling in chronic pulmonary hypertension. Am J Physiol Lung Cell Mol Physiol 293: L1-L8, 2007.

24. Stenmark KR, Davie N, Frid M, Gerasimovskaya E and Das M: Role of the adventitia in pulmonary vascular remodeling. Physiology 21: 134-145, 2006.

25. Arciniegas E, Sutton AB, Allen TD and Schor AM: Transforming growth factor beta 1 promotes the differentiation of endothelial cells into smooth muscle-like cells in vitro. J Cell Sci 103: 521-529, 1992.

26. Zhu P, Huang L, Ge X, Yan F, Wu R and Ao Q: Transdifferentiation of pulmonary arteriolar endothelial cells into smooth muscle-like cells regulated by myocardin involved in hypoxia-induced pulmonary vascular remodelling. Int J Exp Pathol 87: 463-474, 2006.

27. Jones $\mathrm{R}$ and Reid L: Vascular Remodeling in Clinical and Experimental Pulmonary Hypertensions. Portland Press, London, 1995.

28. Yu AY, Shimoda LA, Iyer NV, Huso DL, Sun X, McWilliams R, Beaty T, Sham JS, Wiener CM, Sylvester JT and Semenza GL: Impaired physiological responses to chronic hypoxia in mice partially deficient for hypoxia-inducible factor 1alpha. J Clin Invest 103: 691-696, 1999.

29. Higgins DF, Kimura K, Bernhardt WM, Shrimanker N, Akai Y, Hohenstein B, Saito Y, Johnson RS, Kretzler M, Cohen CD, et al: Hypoxia promotes fibrogenesis in vivo via HIF-1 stimulation of epithelial-to-mesenchymal transition. J Clin Invest 117: 3810-3820, 2007

30. Ansieau S, Bastid J, Doreau A, Morel AP, Bouchet BP, Thomas C, Fauvet F, Puisieux I, Doglioni C, Piccinin S, et al: Induction of EMT by twist proteins as a collateral effect of tumor-promoting inactivation of premature senescence. Cancer Cell 14: 79-89, 2008.

31. Yang J, Mani SA, Donaher JL, Ramaswamy S, Itzykson RA, Come C, Savagner P, Gitelman I, Richardson A and Weinberg RA: Twist, a master regulator of morphogenesis, plays an essential role in tumor metastasis. Cell 117: 927-939, 2004.

32. Sun S, Ning X, Zhang Y, Lu Y, Nie Y, Han S, Liu L, Du R, Xia L, He L and Fan D: Hypoxia-inducible factor-lalpha induces Twist expression in tubular epithelial cells subjected to hypoxia, leading to epithelial-to-mesenchymal transition. Kidney Int 75: 1278-1287, 2009.

This work is licensed under a Creative Commons Attribution-NonCommercial-NoDerivatives 4.0 International (CC BY-NC-ND 4.0) License. 